\title{
A Pilot Study of the Evaluation of Using Antibiotics in Sepsis Patients in Palu, Indonesia
}

\author{
Alwiyah Mukaddas, Tatat Rahmita Utami, Amelia Rumi* \\ Department of Pharmacy, Faculty of Mathematics and Natural Sciences, Tadulako University, Palu, Indonesia
}

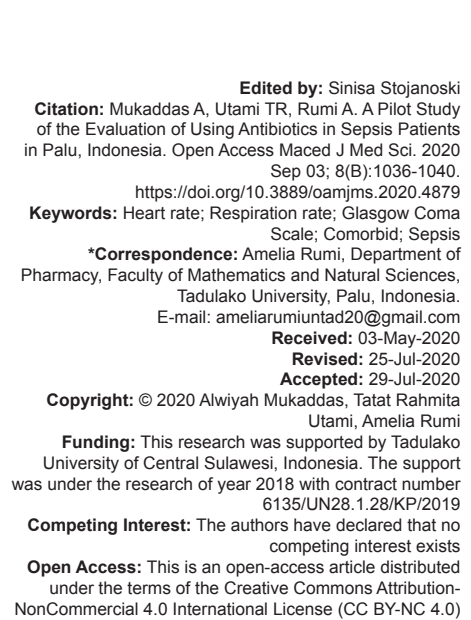

\section{Introduction}

Sepsis is the condition in which the patient goes through periods of bacteremia, systemic inflammatory response syndrome, sepsis, severe sepsis, shock septic, or multiple organ dysfunction syndrome which has gone into overlap and suggests a progressive deterioration physiology [1]. Clinically, sepsis is differentiated based on sepsis, severe sepsis, and sepsis shock. Severe sepsis can be seen from the dysfunction of one organ or organ system while septic shock can be seen from the presence of organ or organ system dysfunction and hypotension that does not improve with fluid resuscitation [2].

Therapy with antibiotics appropriately and adequately is still one of the factors supporting success in the treatment of sepsis which is proven to reduce mortality in sepsis and sepsis cycles [3]. Antibiotics are antimicrobial product obtained from substances derived from the microorganism or a synthetic substance which can kill or inhibit the work of another microorganism [4]. Antibiotics are given immediately during the $1^{\text {st }} \mathrm{h}$ after being diagnosed with severe sepsis and septic shock. Where every hour, the administration of antibiotics is delayed because delays in administering antibiotics can cause death, where every hour the delay antibiotic administration is associated with $6 \%$ increase in mortality [5].

According to Dewi (2014), sepsis has caused most of the deaths in hospital Dr. Cipto Mangunkusumo Jakarta in 2010. Number of patients with sepsis also increased at hospital Dr. M. Djamil Padang, from 2010 to 2013 , 351 patients, 512 patients, 757 patients, and 734 patients [6], [7].

The purpose of this study was to look at the pattern of antibiotic use in sepsis patients and evaluate of antibiotic use in patients with sepsis in terms of days of decreased body temperature, length of stay, respiration rate, heart rate, comorbid factors, and changes in consciousness status.

\section{Ethics approval}

This research has been approved by the Research Ethics Committee of the Faculty of Medicine and Health, Tadulako University, with a letter number 3869/UN28.1.30/KL/2019. 


\section{Materials and Methods}

The subjects of this study were septic patients who were hospitalized and received antibiotic therapy fulfilling the inclusion criteria: Patients aged $>18$ years who had data in their medical record on: Levels of body temperature, length of stay, respiration rate, heart rate, comorbid factors, and changes in the consciousness status. The exclusion criteria: Patient's medical records are incomplete or missing and patients who are suffering shock septic.

\section{Methods and analysis}

The study was a pilot study in which data were collected retrospectively on medical record data from sepsis patients in a private hospital in Palu City, Central Sulawesi, Indonesia. The sample retrieval technique is a total sampling by gathering all medical records of sepsis patients that meet the criteria of inclusion and exclusion because of a very small number of samples. The baseline score when patients were first diagnosed sepsis and the value of evaluation was seeing the effectiveness of the antibiotic usage being made from the $1^{\text {st }}$ day of dropping body temperature and then measuring other parameters such as heart rate, respiration rate, and Glasgow Coma Scale (GCS). Descriptive analysis using the univariate method for see changes in heart rate, respiration rate, changes in the patient's consciousness status, before and after using antibiotics.

\section{Results}

\section{Demographic characteristics}

Table 1 shows that of the 14 patients with sepsis, 7 patients were male $(50 \%)$, comparable to the number of female patients also 7 people (50\%). The age range patients were $46-55,56-65$, and more than 65 years all categories by 4 patients $(28.6 \%)$.

Table 1: Demographic characteristics of sepsis patients in Palu, Indonesia

\begin{tabular}{lll}
\hline Characteristics & Number of sepsis patients $(\mathrm{n}=14)$ & Percentage \\
\hline Gender & & \\
Male & 7 & 50 \\
Female & 7 & 50 \\
Age & & \\
$26-35$ & 1 & 7.1 \\
$36-45$ & 1 & 7.1 \\
$46-55$ & 4 & 28.6 \\
$56-65$ & 4 & 28.6 \\
$>65$ & 4 & 28.6 \\
\hline
\end{tabular}

\section{Clinical manifestations}

Table 2 shows that the dominant clinical manifestations in 14 sepsis patients were fever, leukocytosis, tachycardia, decreased consciousness with a percentage of $85.8 \%$, tachypnea with a percentage of $71.4 \%$, and leukopenia with two patients.

Table 2: Clinical manifestations in sepsis patients in Palu, Indonesia

\begin{tabular}{lll}
\hline Symptoms & Number of sepsis patients & Percentage \\
\hline Fever & 12 & 85.8 \\
Leukocytosis & 12 & 85.8 \\
Leukopenia & 2 & 14.2 \\
Tachypnea & 10 & 71.4 \\
Tachycardia & 12 & 85.8 \\
Loss of consciousness & 12 & 85.8 \\
\hline
\end{tabular}

\section{Diagnosis}

Table 3 shows the diagnosis of sepsis patients dominated by diabetes mellitus (DM) (28.6\%), CKD (21.4\%), pneumonia (14.2\%), and AKI (14.2\%).

Table 3: Diagnosis of sepsis patients in Palu, Indonesia

\begin{tabular}{lll}
\hline Diagnosis & Number of sepsis patients & Percentage \\
\hline Type 2 diabetes & 4 & 28.6 \\
CKD & 3 & 21.4 \\
Pneumonia & 2 & 14.2 \\
AKI & 2 & 14.2 \\
\hline CKD: Chronic kidney disease, AKI: Acute kidney injury.
\end{tabular}

\section{Comedication}

Table 4 shows that other therapies combined with antibiotics were ranitidine $(71.4 \%)$, paracetamol $(64.2 \%)$, and dexamethasone (57.1\%).

Table 4: Medication profile of sepsis patients in Palu, Indonesia

\begin{tabular}{lll}
\hline Other therapies used & Number of sepsis patients & Percentage \\
\hline Ranitidine & 10 & 71.4 \\
Omeprazole & 6 & 42.9 \\
Sucralfate & 3 & 21.4 \\
Lansoprazole & 1 & 7.1 \\
Ketorolac & 4 & 28.5 \\
Natrium Diclofenac & 1 & 7.1 \\
Metamizole sodium & 1 & 7.1 \\
Mefenamic acid & 1 & 7.1 \\
Paracetamol & 9 & 64.2 \\
Amino acid & 2 & 14.2 \\
Curcuma xanthorrhiza & 1 & 7.1 \\
PotassiumChloride & 1 & 7.1 \\
Vitamin B1 & 4 & 28.5 \\
Vitamin B6 & 4 & 28.5 \\
Vitamin B12 & 4 & 28.5 \\
Novorapid & 3 & 21.4 \\
Levemir & 2 & 14.2 \\
Metformin & 1 & 7.1 \\
Domperidone & 2 & 14.2 \\
Ondansetron & 2 & 14.2 \\
Loperamide & 1 & 7.1 \\
Furosemide & 1 & 7.1 \\
Metilprednisolone & 1 & 7.1 \\
Dexamethasone & 8 & 57.1 \\
Norepinephrine & 1 & 7.1 \\
Dopamine & 1 & 7.1 \\
Allopurinol & 1 & 7.1 \\
Alprazolam & 1 & 7.1 \\
Citicoline & 4 & 28.5 \\
Propranolol & 1 & 7.1 \\
Loratadine & 1 & 7.1 \\
Ambroxol & 1 & 14.2 \\
Phenytoin & 14 & 7.1 \\
Infuse NaCl 0,9 \% & & 100 \\
Infuse ringer lactate & & 100 \\
\hline & &
\end{tabular}

\section{Antibiotic therapy evaluation heart rate}

Table 5 shows that there was a change from the baseline heart rate from $110.8 \mathrm{bpm}$ to $88.4 \mathrm{bpm}$ 
where the evaluations show the average heart rate of patients become normal after using antibiotics.

Table 5: Heart rate of sepsis patients in Palu, Indonesia

\begin{tabular}{lllll}
\hline & Mean value & & & Percentage \\
\cline { 2 - 4 } & Baseline & Evaluation & Deviation & \\
\hline Heart rate & 110.8 & 88.4 & 22.4 & 20.21 \\
\hline
\end{tabular}

\section{Respiration rate}

Table 6 shows that there has been a change from the baseline respiration rate which was valued at $30.8 \mathrm{x} /$ min-22.1 $\mathrm{x} / \mathrm{min}$ and evaluations show the average of patients respiration rate to normal after using antibiotics.

Table 6: Respiration rate of sepsis patients in Palu, Indonesia

\begin{tabular}{lllll}
\hline & \multicolumn{2}{l}{ Mean value } & & Percentage \\
\cline { 2 - 4 } & Baseline & Evaluation & Deviation & \\
\hline Respiration rate & 30.8 & 22.1 & 8.7 & 28.2 \\
\hline
\end{tabular}

\section{Day of decreasing body temperature}

Table 7 shows that there was a change from the previous baseline body temperature of $38.47^{\circ} \mathrm{C}-37.87^{\circ} \mathrm{C}$ where the initial body temperature was diagnosed with a decline during antibiotics but is still in category fever.

Table 7: Body temperature of sepsis patients in Palu, Indonesia

\begin{tabular}{ll}
\hline Baseline $\left({ }^{\circ} \mathrm{C}\right)(\mathrm{n}=14)$ & Evaluation $\left({ }^{\circ} \mathrm{C}\right)$ \\
\hline 38.47 & 37.87 \\
\hline
\end{tabular}

\section{GCS}

Table 8 shows that there were changes from the previous baseline GCS 9-7. However, the evaluation results showed that patients remained in somnolence state, but the GCS scores decreased. It suggests that the patient's conscious status has not improved or has not increased the GCS score after antibiotic therapy.

Table 8: GCS of sepsis patients in Palu, Indonesia

\begin{tabular}{lllll}
\hline & Mean value & & Percentage \\
\cline { 2 - 4 } & Baseline & Evaluation & Deviation & \\
\hline GCS & 9 & 7 & 2 & 24.8 \\
\hline GCS: Glasgow Coma Scale. & & &
\end{tabular}

\section{Comorbidities factor}

Table 9 shows that sepsis patients were dominated by patients with more than 1 comorbidity $(57.1 \%)$ compared to those who only had one comorbidity (42.9\%).

Table 9: Comorbidities factors of sepsis patients in Palu, Indonesia

\begin{tabular}{lll}
\hline Comorbid of factors & Number of sepsis patients $(\mathrm{n}=14)$ & Percentage \\
\hline One comorbid & 6 & 42.9 \\
More than 1 comorbid & 8 & 57.1 \\
\hline
\end{tabular}

\section{The evaluation of antibiotics therapy}

Table 10 shows the total number of antibiotic use. Use of single antibiotic therapy as ceftriaxone, meropenem, cefuroxime, and cefobactam was with a percentage of $14.2 \%$ and combination of antibiotic therapy ceftriaxone + metronidazole was $28.6 \%$.

Table 10: Medications antibiotics profile of sepsis patients in Palu, Indonesia

\begin{tabular}{llll}
\hline Therapy & Antibiotics therapy & $\begin{array}{l}\text { Number of sepsis } \\
\text { patients }(\mathrm{n}=14)\end{array}$ & $\begin{array}{l}\text { Percentage } \\
(\%)\end{array}$ \\
\hline Single & Ceftriaxone & 2 & 14.2 \\
& Meropenem & 2 & 14.2 \\
& Cefobactam & 2 & 14.2 \\
& Cefotaxime & 1 & 7.1 \\
& Cefuroxime & 2 & 14.2 \\
& Ceftriaxone + metronidazole & 4 & 28.6 \\
& Ceftriaxone + ciprofloxacin & 1 & 7.1 \\
& Metronidazole + meropenem & 1 & 7.1 \\
& Metronidazole + cefadroxil & 1 & 7.1 \\
& Metronidazole + cefixime & 1 & 7.1 \\
& Metronidazole + cefuroxime & 1 & 7.1 \\
& Metronidazole + gentamicin & 1 & 7.1 \\
& Meropenem + ceftazidime & 1 & 7.1 \\
& Meropenem + cefuroxime & 1 & 7.1 \\
\hline
\end{tabular}

\section{Length of stay}

Table 11 shows that half of the patients with a diagnosis of sepsis in this study $(85.8 \%)$ were treated for 2-10 days, $7.1 \%$ of patients were treated for more than 10 days, and $7.1 \%$ of patients were treated for more than 20 days.

Table 11: Length of stay of sepsis patients in Palu, Indonesia

\begin{tabular}{llll}
\hline Length of stay & Number of sepsis patients $(n=14)$ & Percentage & Note \\
\hline $0-10$ days & 12 & 85.8 & Death cases \\
$10-20$ days & 1 & 7.1 & Death case \\
$>20$ days & 1 & 7.1 & Death case \\
\hline
\end{tabular}

\section{Discussion}

In this study, the age of most sepsis patients was between the ages of $46-55,56-65$, and more than 65 years as many as 4 patients $(28.6 \%)$. This result is consistent with the research conducted by Nurul that the proportion of elderly patients died of more sepsis. This is confirmed in the Bhattacharjee study that elderly people have the greatest risk of developing sepsis with its various complications, including higher mortality. The risk of sepsis in the elderly increases due to various causes such as comorbidities, decreased kidney and liver function, and low body response to overcome sepsis [8], [9].

Sepsis is not influenced by gender but is influenced by age and the type of underlying disease. Other studies have found mixed results, namely, that women only $10 \%$ of developing sepsis and dying [10].

Most clinical manifestations are fever, leukocytosis, tachycardia, and changed level of consciousness. The fever is the most common symptom. In this study, 12 patients entered the hospital with body temperature starting from $38^{\circ} \mathrm{C}$ to $40^{\circ} \mathrm{C}$ in the category of fever and generally indicated an infection, but two patients were admitted to the hospital with a normal body temperature of $36^{\circ} \mathrm{C}-6.2^{\circ} \mathrm{C}$ which generally indicated 
no presence of infection. Leukocytosis is a common symptom in patients diagnosed with sepsis. Mild disorientation or confusion usually occurred in the elderly. Other manifestations include anxiety and agitation.

The diagnosis of sepsis is dominated by DM. Patients with DM are at risk of infection and sepsis. Sources of bacterial infections that cause sepsis, one of which is a bacterial infection in wounds with long periods (chronic wounds). Chronic injuries often occur in people with DM where there is damage to blood vessels, innervation, and decreased endurance which causes bacteria to thrive and wounds are difficult to heal. Bacteria can enter the bloodstream and spread throughout the body, resulting in sepsis reactions to so why DM is a deteriorating factor of comorbidity in sepsis.

Most of the seriously ill patients admitted to the hospital's intensive care unit showed signs of gastric mucosa damage. Patients with sepsis who were treated received prophylactic stress ulcer therapy, namely, $\mathrm{H}_{2}$ blocker/PPI/combination (ranitidine and omeprazole). In adult sepsis, patient corticosteroids were not given if fluid resuscitation is adequate and the use of vasopressor drugs achieves stable hemodynamics. If the target is not achieved, then corticosteroids need to be given [2]. Corticosteroids that are recommended by the guidelines for SMF Internal Medicine Clinical Guidelines from 2013 for Dr. Moewardi Surakarta (PPK) were methylprednisolone and dexamethasone.

The patient's heart rate monitoring results showed that there was a change from the baseline heart rate which was previously worth 110.8 bpm$88.4 \mathrm{bpm}$ and the evaluation results showed that the patient's heart rate was normal after using antibiotics. Tachycardia is an early sign of sepsis. In the study, it was reported that the initial heart rate in sepsis patients was $120 \mathrm{x} / \mathrm{min}$. Decrease in heart rate to a $106 \mathrm{x} / \mathrm{min}$ in the first $24 \mathrm{~h}$ improves life rates [11].

The results of monitoring the patient's respiration rate showed that there was a change from the baseline respiration rate which was previously at $30.8 \mathrm{x} / \mathrm{min}-22.1 \mathrm{x} / \mathrm{min}$ and the evaluation results showed the average respiration rate, the patient becomes normal after using antibiotics. Respiratory rate was one of the assessment parameters which significantly affected mortality in sepsis patients compared to other variables. A study that states that the inaccuracy of the implementation of the surviving sepsis campaign is mainly related to the availability of mechanical ventilation and the adequacy of calories in the first $48 \mathrm{~h}$ will increase the risk of mortality [12].

The results of monitoring the patient's body temperature showed that there was a significant difference between body temperature at the initial diagnosis and temperature decreased during antibiotic use. For a decrease in temperature seen from the day, when the patient starts antibiotic therapy, but the body temperature can rise again. In this study, the average decrease in body temperature occurred after 1 day the patient was given antibiotics.

The baseline GCS score is 9 and the evaluation average of 7 is that the patient remains in somnolence state, but the GCS score is decreased. Somnolence is a condition in which the patient is in a deep drowsy condition, but can still be awakened using stimulation. In the study, there has been no improvement in the GCS score after antibiotics were given. This comparably studies made by Alalawi et al. that GCS score not only predicts development of sepsis but also has prognostic value. Patients who have low GCS have a high mortality rate [13].

Comorbidity factors are one of the other factors that can increase the mortality of patients with sepsis. The results of this study indicate that patients who die earlier are patients who have one comorbid disease with 1-4 days of hospital stay and have a fairly fatal type of comorbid disease, namely, acute hepatitis, AKI, hepatic encephalopathy, and CKD. Patients who survived for a long time were patients who had more than 1 comorbid disease with a length of stay in hospital 1-24 days later had fatal types of comorbid diseases, namely, DM, diabetic ulcer, bronchitis, pneumonia, CKD and comorbid diseases that were not too fatal namely dyspepsia, pancytopenia, anemia, gout arthritis, obstructive ileus, and peritonitis.

Cephalosporin group of antibiotics, especially ceftriaxone, is widely used as single or combination therapy ceftriaxone is a third-generation broad-spectrum cephalosporin antibiotic for intravenous or intramuscular administration. It is one of the most commonly used antibiotics due to its high antibacterial potential, broad spectrum of activity, and low potential for toxicity. Most widely (commonly) used combination of antibiotics is ceftriaxone and metronidazole with a percentage of $28.6 \%$. Ceftriaxone is a third-generation cephalosporin group. Its activity against Gram-negative germs is stronger and wider. Ceftriaxone cannot overcome infection from anaerobic bacteria so it is combined with metronidazole which can overcome infection from anaerobic bacteria. Anaerobic bacteria that cause pneumonia are Klebsiella pneumoniae. The combination of cephalosporins and metronidazole is effective as empirical therapy in due leg infection will increase the complexity of antibacterial activity which can fight Gram-positive and -negative bacteria too anaerobic bacteria [14], [15].

In this study, more than half of patients $(85.8 \%)$ were treated for $2-10$ days, $7.1 \%$ of patients were treated for more than 10 days, and $7.1 \%$ of patients were treated for more than 20 days. Elderly age, comorbidity, complications, and failure in early diagnosis of sepsis are predictors for the length of stay in septic patients [10].

All patients who suffer from sepsis (100\%) leave the hospital in a state of death. This can be caused by several things, namely, patients late for hospital admission, patients diagnosed late sepsis, antibiotics are given are not effective, and the presence of complications or comorbid factors. In this study, antibiotic administration 
was not rational because in these patients, no culture tests were carried out, so antibiotic use was carried out empirically, which was said to avoid the use of a combination of antibiotics for therapy for a long time.

\section{Conclusion}

Based on the research conducted, it can be concluded that the average value for body temperature after using antibiotics is still in the category of fever, heart rate, and respiration rate which are the normal category, patient consciousness is still at the level of somnolence even though patient's GCS score has decreased, and patients with one factor of comorbidities are faster in death because they have a fatal type of comorbid such as acute of hepatitis, coma hepatikum, and acute kidney injury. Prompt and appropriate early treatment at the time of arrival can indicate a prognosis in which the patient is more likely to accept all the necessary interventions including blood cultures and therefore definitive antibiotic therapy can be administered.

\section{Acknowledgment}

The researchers thank to the Director, Head, and staff of the Medical Record Division of the Undata General Hospital, and all parties who have provided assistance in the implementation process until the completion of this research. The acknowledgment goes also to the Faculty of Mathematics and Natural Sciences of Tadulako University, which has funded this research.

\section{References}

1. Dipiro JT, Talbert RL, Yee GC, Matzke GR, Wells BG, Posey LM Pharmacotherapy: A Pathophysiologic Approach. $10^{\text {th }}$ ed. United State: McGraw Hill; 2017.
2. Dellinger R, Levy MM, Rhodes A, Rhodes A, Annane D, Gerlach $\mathrm{H}$, et al. Surviving sepsis campaign: International guidelines for management of severe sepsis and septic shock. Intensive Care Med. 2013;39:165-228. https://doi.org/10.1007/ s00134-012-2769-8

3. Rhodes A, Evans L, Alhazzani W, Levy M, Antonelli M, Ferrer $\mathrm{R}$, et al. Surviving Sepsis Campaign: International Guidelines for Management of Sepsis and Septic Shock: 2016. Crit Care Med. 2017;45(3):486-552. https://doi.org/10.1097/ ccm.0000000000000192 PMid:28098591

4. Seputra K, Tarmono T, Noegroho B, Mochtar C. Guideline Does The Urinary Tract Infection and Male Genitalia. $2^{\text {nd }}$ ed. Surabaya: Indonesian Urological Association; 2015.

5. Soong J, Sony N. Sepsis: Recognition and treatment. Clin Med. 2012;12(3):276-80.

PMid:22783783

6. Dewi SA, Pudjiaji AH, Djer MM, Supriyanto B, Syarif DR, Kurniati N. Risk Factors That Play a Role in Sepsis Mortality. Jakarta: The University of Indonesia; 2014.

7. Hidayati, Arifin H, Raveinal R. The Study of Antibiotic Use in Patients Sepsis with Kidney Disease. J Sains Farm Klin. 2016.

8. Ahmad N. The Correlation between the SOFA Score and Length of Stay Sepsis Patient at the Intensive Care Unit. Semarang: Dr. Kariadi Hospital; 2015

9. Bhattacharjee $P$, Edelson $D$, Churpek MM. Identifying patients with sepsis on the hospital wards. Chest. 2017;151(4):898-907. https://doi.org/10.1016/j.chest.2016.06.020

10. Tambayong RN, Diana CL, Lucky K. Profile of Sepsis Patients in Dr. R. D Kandou Manado Hospital. Manado: Journal of E-Clinic; 2016.

11. Indonesian Intensive Care Doctor Association. The Alignment of Sepsis and Septic Shock Optimize Fasthugsbid. Jakarta: Indonesian Intensive Care Doctor Association; 2014

12. Yuliarto $\mathrm{S}$, Kadafi KT, Nugrahani IT, Aminingrum $\mathrm{R}$, Asariati $\mathrm{H}$. The barrier of surviving sepsis campaign guideline 2012 implementation for children at tertiary hospital. Malang. Brawijaya Med J. 2014;28(1):4-6. https://doi.org/10.21776/ ub.jkb.2014.028.01.11

13. Alalawi MS, Aljabran HA, Alkhamri AM, Alwahbi AM, AIQarrash ZA, Iraqi HA, et al. Glasgow coma scale in anticipation of sepsis and septic shock. Egypt J Hosp Med. 2017;69(6):26636. https://doi.org/10.12816/0042245

14. Leekha S. General principles of antimicrobial theraphy. Mayo Clin Proc. 2011;86(2):156-67. PMid:21282489

15. Apriliana W. Rational Evaluation Use of Antibiotics Prophylaxis to Acute Appendicitis Operation in Adults and Geriatric Patients at Bethesda Hospital in Yogyakarta, Thesis, School of Pharmacy. Indonesia: Sanata Dharma Univesity; 2017. 